\title{
Mitigating Children's Pain and Anxiety during Blood Draw Using Social Robots
}

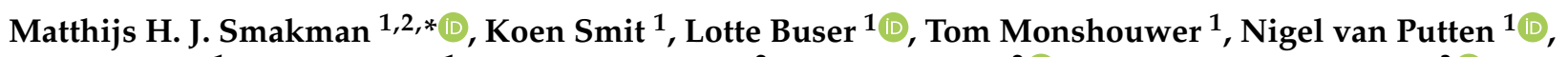 \\ Thymen Trip ${ }^{1}$, Coen Schoof ${ }^{1}$, Daniel F. Preciado ${ }^{2}$, Elly A. Konijn ${ }^{2}{ }^{(1)}$, Esther M. van der Roest ${ }^{3}(1)$ \\ and Wouter M. Tiel Groenestege ${ }^{3}$
}

1 Institute for Information and Communication Technology, HU University of Applied Sciences Utrecht, Heidelberglaan 15, 3584 CS Utrecht, The Netherlands; koen.smit@hu.nl (K.S.); lotte.buser@student.hu.nl (L.B.); tom.monshouwer@student.hu.nl (T.M.); nigel.vanputten@student.hu.nl (N.v.P.); thymen.trip@student.hu.nl (T.T.); coen.schoof@student.hu.nl (C.S.)

2 Department of Communication Science, Vrije Universiteit Amsterdam, De Boelelaan 1105, 1081 HV Amsterdam, The Netherlands; d.f.preciadovanegas@vu.nl (D.F.P.); elly.konijn@vu.nl (E.A.K.)

3 Central Diagnostic Laboratory, University Medical Center Utrecht, Heidelberglaan 100, 3584 CX Utrecht, The Netherlands; e.m.vanderroest@umcutrecht.nl (E.M.v.d.R.); w.m.tielgroenestege@umcutrecht.nl (W.M.T.G.)

* Correspondence: matthijs.smakman@hu.nl

Citation: Smakman, M.H.J.; Smit, K.; Buser, L.; Monshouwer, T.; van Putten, N.; Trip, T.; Schoof, C.; Preciado, D.F.; Konijn, E.A.; van der Roest, E.M.; et al. Mitigating Children's Pain and Anxiety during Blood Draw Using Social Robots. Electronics 2021, 10, 1211. https:// doi.org/10.3390/electronics10101211

Academic Editor: Michael Wehner

Received: 23 April 2021

Accepted: 16 May 2021

Published: 19 May 2021

Publisher's Note: MDPI stays neutral with regard to jurisdictional claims in published maps and institutional affiliations.

Copyright: (c) 2021 by the authors. Licensee MDPI, Basel, Switzerland. This article is an open access article distributed under the terms and conditions of the Creative Commons Attribution (CC BY) license (https:// creativecommons.org/licenses/by/ $4.0 /)$.

\begin{abstract}
Young pediatric patients who undergo venipuncture or capillary blood sampling often experience high levels of pain and anxiety. This often results in distressed young patients and their parents, increased treatment times, and a higher workload for healthcare professionals. Social robots are a new and promising tool to mitigate children's pain and anxiety. This study aims to purposefully design and test a social robot for mitigating stress and anxiety during blood draw of children. We first programmed a social robot based on the requirements expressed by experienced healthcare professionals during focus group sessions. Next, we designed a randomized controlled experiment in which the social robot was applied as a distraction method to measure its capacity to mitigate pain and anxiety in children during blood draw in a children's hospital setting. Children who interacted with the robot showed significantly lower levels of anxiety before actual blood collection, compared to children who received regular medical treatment. Children in the middle classes of primary school (aged 6-9) seemed especially sensitive to the robot's ability to mitigate pain and anxiety before blood draw. Children's parents overall expressed strong positive attitudes toward the use and effectiveness of the social robot for mitigating pain and anxiety. The results of this study demonstrate that social robots can be considered a new and effective tool for lowering children's anxiety prior to the distressing medical procedure of blood collection.
\end{abstract}

Keywords: social robot; pain; anxiety; distraction; blood draw; children

\section{Introduction}

Children often experience high levels of pain and anxiety during needle procedures in hospitals [1,2]. Research has shown that an anxiety response to needle procedures can cause avoidance behavior, which could be life-threatening to patients who require regular needle procedures [3,4]. Furthermore, distressed young patients slow down medical procedures, which often results in longer waiting times for other patients and a higher workload for healthcare professionals.

Currently, the most commonly used method for mitigating pain and anxiety is distraction, such as verbal or behavioral distraction [2] and that through distraction cards [5]. In the extant literature, there is strong support for distraction and hypnosis as methods for mitigating children and adolescents' needle-related pain and distress, although the quality of available evidence is low according to a systematic review [6]. Multiple studies show that 
the currently used distraction techniques, such as watching cartoons or listening to music, do not have a significant effect during needle procedures [7-9]. Coaching interventions by nurses and parents, such as positive reinforcement, on the other hand, seem to help the child to cope with distress during immunization procedures and venipuncture [10,11]. Other studies related to interactive distractions during blood draw indicate that technological distraction methods, such as digital games, have a high potential in mitigating pain and anxiety for children who undergo medical treatments.

Social robots may provide new opportunities to mitigate children's pain and anxiety during blood draw, as they can be used as a technological distraction method as well as a coaching intervention [12]. Social robots can be defined by three characteristics: (1) having a physical embodiment, (2) having the ability to act (semi-)autonomously, and (3) having the ability to interact with humans by following social norms [13]. Childrobot interaction has become increasingly more prevalent in the fields of education and healthcare [12,14]. In education, social robots are not only used to enhance learning, such as learning multiplication tables [15] and second-language learning [16], but also for affective outcomes, such as lowering anxiety for learning [17].

Social robots are also increasingly applied in a pediatric context [18] and hold significant promise and potential for children in medical settings $[19,20]$. They could, for example, be used to increase the well-being of children during hospitalization [18,21]. Children who interacted with a social robot before and during various medical procedures were reported to show significantly lower levels of fear and pain, compared to children who did receive standard care [22].

There is growing support in the literature for using social robots as a distraction technique during needle proceedings, such as intravenous insertion (IVI). Children who received a social robot-based distraction in addition to standard care during IVI showed a statistically significant reduction in distress, compared to those who only received standard care [23]. Other studies that applied social robot interactions during vaccinations also report on children showing significantly less pain and distress [20]. Recently, Rossi et al. [24] also report that a social robot as a distraction strategy was able to reduce fear and anxiety during vaccination.

Although social robots are being applied for reducing pain and anxiety during vaccination and IVI, no studies are related to the implementation of social robots in pediatric healthcare that provide distraction during blood draw, according to a recent systematic literature review [25]. As aforementioned, support is reported for using social robots for mitigating children's pain and anxiety during needle proceedings. However, the studies thus far were limited in sample size and did not apply an experimental (randomized control) design, which is necessary to draw solid conclusions regarding the effectiveness of an intervention. Therefore, to examine the potential benefits of social robots in children's healthcare, higher-quality research is required [19]. Furthermore, there is a need for studies that focus on the technological development of robots, how robots can best be integrated into the healthcare system, and their effectiveness [19]. Thus, our experimental study focuses on both the design requirements of social robots for mitigating pain and anxiety during blood collection, as well as testing the effectiveness of such a robot in a real-life hospital environment.

This study aims to create a social robot that is able to mitigate children's pain and anxiety during blood collection. Therefore, we conducted several focus group sessions with healthcare professionals of a children's hospital to determine the design, role and activities for the social robot in the process of blood draw. Following, we programmed a social robot and tested whether a social robot used to provide distraction during blood draw would significantly lower anxiety levels in children compared to children receiving standard care. In this randomized controlled experiment, venous or capillary blood was sampled. Venous blood draw is defined as collecting blood by venipuncture, usually in the cubital fossa or hand [26]. Capillary blood draw is defined as collecting blood by puncturing the finger, heel, or earlobe [27]. 
In the next section, we first describe our research method. Thereafter, we present the participants, procedures, data analysis and the results. Finally, we discuss the results and present our conclusions, ending with directions for future research.

\section{Research Method}

This study consisted of two phases. In the first phase (A), we conducted focus group sessions to examine the expectations of health-care professionals related to the design, role and activities for the social robot in the blood draw process. During the second phase (B), we tested the effectiveness of the designed robot in lowering pain and anxiety for children who underwent blood draw.

The study complied with all relevant national regulations, institutional policies and was in accordance with the tenets of the Helsinki Declaration (as revised in 2013) and was reviewed by the Medical Ethics Review Committee (METC-20-678/C) of the Wilhelmina Children's Hospital (WKZ) UMC Utrecht, the Netherlands.

\subsection{Participants}

\subsubsection{Participants of the Focus Group Sessions (Phase A)}

Focus group participants should be selected based on their representativeness of what is being studied [28]. Therefore, via purposive sampling, participants were selected who were deemed the best representatives for designing a social robot used in a pediatric context. The criterion for participants to be included in the focus group sessions was to have at least two months of experience in blood draw of children, such as blood draw employees and pedagogical employees. Through the chief technician of the blood draw polyclinic of the Wilhelmina Children's Hospital (WKZ) in the Netherlands, employees were asked to participate based on the aforementioned criterion.

The number of participants per focus group was partly determined based on external factors. The researchers were forced to minimize the size of the focus groups due to the imposed COVID-19 guidelines as of October 2020, whilst still ensuring its function. Thus, each of the four focus group sessions conducted had three to seven participants. In total, sixteen healthcare professionals (13 female, 3 male), including phlebotomists and pedagogical employees, participated. The ages of the focus group participants were not registered. The health care experience of the participants ranged from beginner to highly experienced health care professionals.

\subsubsection{Participating Children and Their Parents (Phase B)}

All children within the age range of 4 to 12 who needed to undergo blood draw at the WKZ could participate in this study and provided the consent of parents or caretakers. The consent forms used (in Dutch) can be found online at the Open Science Framework (https: / / osf.io/nfa8k/, accessed on 23 April 2021). Children with visual or hearing impairment were excluded. In total, 158 children participated in this study (mean age $=8.26, \mathrm{SD}=2.71$ ). The experimental group consisted of 90 children (mean age $=7.87, \mathrm{SD}=1.74 ; 43$ female, 47 male) and the control group included 68 children (mean age $=8.52, \mathrm{SD}=2.62$; 36 female, 32 male).

In total, 128 parents were surveyed on their views related to the social robots and the blood collection. A total of 69 parents had children in the experimental group, and 59 parents had children participating in the control group. The genders and ages of the parents were not registered.

\subsection{Measures and Materials}

During this study, we made use of a commercially available humanoid robot called NAO (Softbank Robotics, Tokyo, Japan) [29]. The NAO robot was used because it is the most commonly used robot in studies regarding children and healthcare [19], and earlier research on reducing children's pain and anxiety also used this robot [22,24]. 
NAO comes equipped with 7 touch sensors, 4 directional microphones, speakers, speech recognition in 20 languages, $2 \times 2 \mathrm{D}$ cameras with object recognition, and 25 degrees of freedom. It is $58 \mathrm{~cm}$ in height and bipedal with rounded features [29].

A mark $6 \mathrm{NAO}$ was used together with a software platform especially developed for healthcare contexts ('Robots in de Zorg'; by Interactive Robotics). This platform allowed us to either use a no-code solution by dragging and dropping blocks or completely customize the robot's actions using code. Either Python or JavaScript could be used to program the robot. In this case, JavaScript was chosen as the researchers had more experience with this programming language. The JavaScript code was integrated into an HTML web page so that the robot could easily be controlled from a laptop or smartphone. These files were saved locally on the device due to privacy and security considerations. The robot was controlled using a dashboard, and the code was written using the Atom IDE on version 1.53.0. The programs used (in Dutch) can be found online at the Open Science Framework (https://osf.io/nfa8k/, accessed on 23 April 2021).

\subsubsection{Focus Group Sessions (Phase A)}

For this phase, focus group sessions were chosen, as they provide insights into the motivations of participants as well as allow participants to discuss and query each other, thereby refining their ideas [30]. Focus group sessions are a qualitative, face-to-face data collection technique that allows for comprehensive conversations on a topic [31].

\subsubsection{Measurement Instruments for Pain and Anxiety (Phase B)}

To test the effectiveness of the social robot to mitigate children's pain and anxiety during blood draw, we used two scales: the Visual Analogue Scale (VAS) and the Face, Legs, Activity, Cry, and Consolability scale (FLACC).

The Visual Analogue Scale (VAS) is a scale consisting of a horizontal line, with a minimum score of zero (no pain) on the leftmost side, and on the rightmost side, the maximum score of ten (unbearable pain). The patient is instructed to indicate the sensation experienced by marking the scale, either verbally or by using fingers to indicate the marking on the scale. VAS can be used for multiple goals, such as evaluating pain and anxiety [32]. In this study, VAS-A was used, which is a variation of VAS used to identify the extent of anxiety experienced by a patient (Kindler et al., 2000). The VAS-A scale was chosen to assess anxiety, as it has shown to be a validated tool for assessing anxiety of children on a $0-10$ scale [33].

The level of pain was measured using the Face, Legs, Activity, Cry, and Consolability scale (FLACC). The FLACC scale is one of the most commonly used scales in research for assessing children's pain [34]. The FLACC scale rates the pain experienced by the patient on a $0-2$ scale, across five types of behavior: face, legs, activity, crying, and consolability The questionnaires used (in Dutch) can be found online at the Open Science Framework (https://osf.io/nfa8k/, accessed on 23 April 2021).

\subsection{Procedure and Data Collection}

Over a span of three months, from October to December 2020, the data for this study were collected during the two phases. During the first phase (A), four focus groups were conducted. During the second phase (B), data of 158 participating children, who underwent blood collection, were collected. In this section, we further detail the procedure and data collection of the two phases.

\subsubsection{Procedure and Data Collection Regarding the Focus Group Sessions (Phase A)}

The focus group sessions were facilitated by two researchers whom both had experience in qualitative data collection and social robot design and interaction.

The focus group sessions consisted of two steps: inductive and deductive. The inductive step started with an introduction, along with an explanation of the purpose and procedures of the session. After the introduction, participants were asked what they would 
consider desired functions for a social robot as a tool to mitigate children's pain and anxiety. These requirements were then shared, discussed, and refined by the participants.

During the deductive step, a demonstration of the NAO robot was provided after which the participants were asked to provide their views on its attributes and behavior. The robot interacted with the participants and, among other activities, danced, joked, and sang. Applying both an inductive and deductive steps prevented participants from limiting their ideas to the functions observed during the demonstration of the NAO robot. All sessions were recorded and transcribed, and later used during the coding process. Participants provided verbal consent for the audio recordings being made.

\subsubsection{Procedure and Data Collection Related to Children's Pain and Anxiety (Phase B)}

Each day of measuring consisted of two randomly assigned shifts, either with or without the NAO robot. One group received standard care, including social robot distraction (experimental group) and the other group received standard care without a robot (control group).

When children and their parents arrived at the blood draw policlinic of the hospital, they were informed of the possibility to participate in this study. If they were interested, they were provided with an information sheet, asked for their consent and asked to provide contextual information. Parents and children were also informed that they, at any time, could decide to stop taking part in the study. The parents in the control group and the experimental group both answered questions regarding the children's level of anxiety when arriving at the hospital and how often their child needed blood draw. The parents in the experimental group answered three additional questions regarding their child's knowledge of robotics, parents' knowledge of robotics, and if they thought their child would like to interact with a robot. This contextual information was inquired about because it could affect the results. For example, a child's prior experiences with blood draw can affect subsequent anxiety levels during blood draw [3,4]. Each question was to be answered using a Likert-type scale ranging from negative (one) to positive (six) [35], except for the following question: "How often does your child undergo blood draw?". Six-point scales were chosen because this lacks a neutral point, forcing people to decide their level of agreement with the statement [36,37]. When answering the baseline questions, the parents and children were aware to which group they belonged (with or without robot). The questionnaires used for this study (in Dutch) can be found in the online appendix at the Open Science Framework (https:/ / osf.io/nfa8k/, accessed on 23 April 2021).

After both the child and parent consented and the contextual information was registered, they proceeded to the regular blood drawing room. In the experimental group, the robot was present in this room.

Following the advice from health care professionals derived from the focus group sessions, we based the three programs on the ages and maturity levels of children that, overall, corresponded with the three categories of division in Dutch primary education (lower, middle, and higher classes, encompassing ages 4-6, 6-9, and 9-12, respectively). A description of each program and the allocated categories are shown in Table 1.

Therefore, three programs for the social robot were created in HTML and JavaScript using the text editor Atom (version 1.53.0, Github, SF, USA, 2020) along with the "Robots in the classroom" API (version Kamelia V2, Interactive Robotics, Delft, the Netherlands, 2020). The API served as a bridge between our programs and the NAO robot's hardware. These programs were executed by the social robot during blood draw to distract the child. 
Table 1. Features of the robot programs used and their target groups.

\begin{tabular}{|c|c|c|}
\hline Program & Category & Description of Program \\
\hline A & $\begin{array}{l}\text { Lower classes in } \\
\text { primary education } \\
\text { (aimed at children } \\
\text { aged } 4-6 \text { ) }\end{array}$ & $\begin{array}{l}\text { First, the robot introduced itself and told the child } \\
\text { what the robot was about to do. Thereafter, the robot } \\
\text { asked questions about the child's favorite color and } \\
\text { animal. The robot continued to sing a song from a } \\
\text { Dutch series of picture books (Miffy). Then, the } \\
\text { robot danced to the song "head, shoulders, knees } \\
\text { and toes". Finally, the robot told the children that } \\
\text { they did well and said goodbye. }\end{array}$ \\
\hline B & $\begin{array}{l}\text { Middle classes in } \\
\text { primary education } \\
\text { (aimed at children } \\
\text { aged 6-9) }\end{array}$ & $\begin{array}{l}\text { First, the robot introduced itself and told the child } \\
\text { what the robot was about to do. Thereafter, the robot } \\
\text { asked questions about the child's hobbies. The robot } \\
\text { continued demonstrating its hobbies: Tai chi and } \\
\text { playing saxophone. Afterward, the robot told some } \\
\text { jokes and danced to "head, shoulders, knees and } \\
\text { toes". Finally, the robot told the children that they } \\
\text { did well and said goodbye. }\end{array}$ \\
\hline $\mathrm{C}$ & $\begin{array}{l}\text { Higher classes in } \\
\text { primary education } \\
\text { (aimed at children } \\
\text { aged 9-12) }\end{array}$ & $\begin{array}{l}\text { First, the robot introduced itself and told the child } \\
\text { what the robot was about to do. The robot then } \\
\text { demonstrated its hobbies: telling jokes and playing } \\
\text { saxophone. Thereafter, the robot danced to the song } \\
\text { named Gangnam Style by Psy, and to a 1970s' style } \\
\text { dance. Finally, the robot told the children that they } \\
\text { did well and said goodbye. }\end{array}$ \\
\hline
\end{tabular}

Children were primarily assigned to a program based on their age. The classification was based on the focus group sessions and had a small overlap for children aged 6 and 9 . Children (aged 6 or 9) in the experimental group were assigned to the appropriate category based on their perceived maturity level by the phlebotomist, and children (aged 6 or 9) in the control group were randomly assigned to a category. In the case of a special needs child, the phlebotomist assigned the category to ensure that an appropriate program was chosen for the child.

Three phlebotomists of the policlinic Wilhelmina Children's Hospital (WKZ) in the Netherlands were assigned to this study and received an in-depth briefing on the experiment and on how to use the measurement scales by two researchers. Additionally, a training was performed to get familiarized with using the NAO-robot during blood draw. Finally, the phlebotomist performing the blood draw was complemented with one researcher being present during the blood draws to ensure the proper functioning of the robot.

During the blood draw procedure, the health care professional performing the blood draw recorded the VAS-A and FLACC scores of the children, before, during and after blood collection. Furthermore, after the blood draw, children were asked to indicate their level of anxiety based on the VAS-A scale, with a smiley rating scale similar to a scale used in earlier research on social robots and children [24]. The parents of children participating in the experimental group were asked to answer two additional questions regarding their perception of the effectiveness of the robot for mitigating their child's pain and anxiety. All collected data were fully anonymized by the phlebotomist.

\section{Data Analysis}

\subsection{The Design of the Robot (Phase A)}

After the focus group sessions were conducted, the recordings were transcribed after which they were thematically analyzed using the qualitative data analysis tool ATLAS.ti 8 (version 9, ATLAS.ti, Berlin, Germany, 2020). Thematic analysis was accomplished using Corbin and Strauss's coding approach [28]. 
The open coding process was executed concurrently with the axial coding process as coding labels were already present before the coding process. To mitigate researcher bias and maximize richness in perspectives, four researchers individually coded (parts of) sentences that were deemed relevant to the potential design of the social robot [38]. The goal of this coding process was to provide the selective coding process with traceable and comprehensive coding structures, for the resulting design requirements to be transparent. To achieve this, the researchers used the Toulmin framework [39].

After the researchers concluded the individual coding process, the codes of all focus groups were combined (Simple Percentage Agreements: FG 1 52.0\% FG 2 48.6\% FG 3 47.1\% FG 4 42.3\%), after which they were reviewed and recoded collaboratively. Finally, the selective coding process was performed by coding the relevant claim, ground, and warrant-structures into design requirements for the social robot. This was achieved by categorizing clusters of the claim, ground, warrant-structures into different categories related to the potential requirements of the social robot. For example: "Design ideas dancing" and "Design ideas interaction". Within these categories, attribution analysis was applied.

Attribution analysis is a type of analysis in which the frequency of certain characterizations or descriptors is counted [40]. In the case of this study, the frequency in which single ideas were mentioned during the focus group were identified as characterizations or descriptors. Examples of these ideas are "The robot should dance after the blood draw" and "The child should not participate in dancing during blood draw". The final design of the social robot's program was based on prioritization by frequency, as the researchers deemed frequency to be proportional to the importance of an idea [41]. The MoSCoW method was used for requirement prioritization [42]. With this method, we prioritized the requirements in three different classes: must have (the requirement is utterly important and must be included in the design), should have (the requirement is important and should be included in the design), could have (this requirement is not important but could be interesting once included).

When the selective coding process was finished, a demonstration of the resulting design of the robot was reviewed by an expert in social robotics and an expert in the field of blood draw to ensure its quality and appropriateness. Based on this review, parts of the autonomous behavior of the robot were replaced with a static script to smoothen the interaction with the child.

\subsection{Children's Pain and Anxiety (Phase B)}

After the measurements for pain and anxiety were conducted, descriptive analyses were performed on the data. These analyses were performed, using IBM SPSS Statistics (version 24, IBM, Armonk, NY, USA, 2020) for Microsoft Windows.

Two datasets were created to minimize data loss, based on additional demographic data of the parents. Hence, dataset I contained the following information about the child participants: ID number, birth year, gender, date, time, allocated group (experimental group or control group), age group, script category, check for script completion, check for blood draw completion, VAS-A before (VB), VAS-A during (VD), VAS-A after (VA), FLACC before (FB), FLACC during (FD), FLACC after (FA), distraction category, and distraction method. The FLACC (FB, FD, and FA) is the sum of the FLACC attributes across all measurements (before, during, and after). Dataset II contained the same data as dataset I but was extended by the contextual information provided by the parents, and the parents' anxiety indication of their child (VAS-A).

To clean the data, the standard formula (Mean+/ $-2.50 \times$ SD) for outliers was used [43]. In the case that some participant's data were missing, this was marked in SPSS. If a participant's data contained outliers, this participant was excluded from the dataset.

Only non-parametric tests were used due to the data not being normally distributed $(p>0.05)$. The normality was tested using a Kolmogorov-Smirnov test [44]. To compare the experimental group with the control group, a Kruskal-Wallis (unpaired) test was executed 
on dataset I [45]. In the case of significant results $(p<0.05)$, a post hoc test (Mann-Whitney $\mathrm{U})$ was executed to locate the origin of the significant differences [46]. A $p$-value $<0.05$ was chosen as statistically significant as it is standard in similar research (Lee-Krueger, 2019). To test correlations between the VAS-A recorded by the children, previous experience, anxiety (VB, VD, VA, FB, FD, FA), parents' assessment (Q6), and anxiety (VB, VD, VA, FB, FD, FA) of the experimental group, a Spearman's correlation coefficient was executed on dataset II [47]. The output was considered statistically correlated if $p<0.05$ and $r_{\mathrm{s}}$ was close to one or minus one [48].

\section{Results}

\subsection{Phase A: The Design of the Robot}

The focus group sessions resulted in design requirements that were included in the robot design. The requirements with a must have priority were considered essential by healthcare professionals participating in the focus group sessions. Should have requirements were considered important but not necessary for social robots. Requirements labeled could have were desirable but not necessary. The resulting requirements are shown in Table 2 and were all implemented in the NAO robot used during the experiment. For each requirement, we included a name, description, rationale, and priority.

Table 2. Design requirements for a social robot to mitigate pain and anxiety during blood collection in children.

\begin{tabular}{|c|c|c|c|}
\hline Name & Description & Rationale & Priority \\
\hline Interaction & $\begin{array}{l}\text { The robot must be able to interact } \\
\text { with the child during blood draw. }\end{array}$ & $\begin{array}{l}\text { The child must be distracted during the } \\
\text { moment of blood draw. }\end{array}$ & Must-have \\
\hline Word use & $\begin{array}{l}\text { The words used in the interaction } \\
\text { must differ for every age group. }\end{array}$ & $\begin{array}{l}\text { The choice of wording must be understandable } \\
\text { for all children participating. }\end{array}$ & Must-have \\
\hline Behavior & $\begin{array}{l}\text { The robot's behavior must be based } \\
\text { on the age group to which the child } \\
\text { belongs to. }\end{array}$ & $\begin{array}{l}\text { The behavior must be tailored to the child's } \\
\text { social age to be approachable. }\end{array}$ & Must-have \\
\hline Response & $\begin{array}{l}\text { The robot should clarify if it wants } \\
\text { a response from the child. }\end{array}$ & $\begin{array}{l}\text { The child must not be confused by the } \\
\text { expected interactions of the robot. }\end{array}$ & Must-have \\
\hline Movement & $\begin{array}{l}\text { The movement of the robot must } \\
\text { be minimal. }\end{array}$ & $\begin{array}{l}\text { To allow for normal blood draw procedures, } \\
\text { the child must sit still. It is important to make } \\
\text { sure the child does not mimic the robot's } \\
\text { movements during blood draw. }\end{array}$ & Must-have \\
\hline Movement & $\begin{array}{l}\text { The robot must be able to sit, lay } \\
\text { down, and be able to get on its feet } \\
\text { again when it has fallen over. }\end{array}$ & $\begin{array}{l}\text { To ensure distractions for the child, the robot } \\
\text { must be able to recover to normal operation. }\end{array}$ & Must-have \\
\hline Encouragement & $\begin{array}{l}\text { The robot must be able to give } \\
\text { supportive encouragement. }\end{array}$ & $\begin{array}{l}\text { To allow for the robot to successfully support } \\
\text { the child through the blood draw, the robot } \\
\text { provides supportive encouragement. }\end{array}$ & Must-have \\
\hline Games & $\begin{array}{l}\text { The robot must be able to ask } \\
\text { questions or play games with } \\
\text { the child. }\end{array}$ & $\begin{array}{l}\text { To allow for the child to be distracted, games } \\
\text { and quizzes can be used to focus on the robot } \\
\text { and not on the procedure. }\end{array}$ & Should-have \\
\hline Singing & $\begin{array}{l}\text { The robot must be able to use } \\
\text { singing in a sing-along style. }\end{array}$ & $\begin{array}{l}\text { To allow for children aged } 4-9 \text { to be distracted, } \\
\text { singing can be used to focus on the robot and } \\
\text { not on the procedure. }\end{array}$ & Should-have \\
\hline Jokes & $\begin{array}{l}\text { The robot must be able to tell jokes } \\
\text { to children aged } 6-12 \text {. }\end{array}$ & $\begin{array}{l}\text { To allow for children aged } 6-12 \text { to be } \\
\text { distracted, humor can be used to focus on the } \\
\text { robot and not on the procedure. }\end{array}$ & Should-have \\
\hline Original songs & $\begin{array}{l}\text { The robot must play songs with the } \\
\text { original sound. }\end{array}$ & $\begin{array}{l}\text { To allow for the child to be distracted, music } \\
\text { can be used to focus on the robot and not on } \\
\text { the procedure. }\end{array}$ & Should-have \\
\hline $\begin{array}{l}\text { Hand } \\
\text { movements }\end{array}$ & $\begin{array}{l}\text { The robot must be able to use } \\
\text { hand movements. }\end{array}$ & $\begin{array}{l}\text { To mimic human behavior, the robot should be } \\
\text { able to wave goodbye to enforce a } \\
\text { humanlike relationship. }\end{array}$ & Should-have \\
\hline Colors & $\begin{array}{l}\text { The robot must make use of colors, } \\
\text { preferably, primary colors (red, } \\
\text { yellow, and blue). }\end{array}$ & $\begin{array}{l}\text { To allow for the child to be distracted, colors } \\
\text { can be used to focus on the robot and not on } \\
\text { the procedure. }\end{array}$ & Should-have \\
\hline
\end{tabular}


Excluded Requirements: From the derived requirements, a few were excluded due to practical reasons and conflicts of interest. Table 3 details each requirement that was not implemented into the final design of the robot, including the rationale for the rejection.

Table 3. Excluded requirements, not implemented in the robot's design.

\begin{tabular}{|c|c|c|c|}
\hline Name & Description & Rationale & Rationale for Rejection \\
\hline Duration & $\begin{array}{l}\text { The robot must provide } \\
\text { distraction regardless of the } \\
\text { duration of the blood draw. }\end{array}$ & $\begin{array}{l}\text { To ensure the child will be } \\
\text { distracted through the entire } \\
\text { blood draw in case this takes } \\
\text { longer than anticipated. }\end{array}$ & $\begin{array}{c}\text { Because of a lack of programming } \\
\text { skills and time, the project group } \\
\text { was not able to program a script } \\
\text { with a varying duration into the } \\
\text { design of the social robot. }\end{array}$ \\
\hline $\begin{array}{l}\text { Different scripts for } \\
\text { regular basis }\end{array}$ & $\begin{array}{l}\text { The robot must have different } \\
\text { behaviors for children who } \\
\text { undergo blood } \\
\text { draw regularly. }\end{array}$ & $\begin{array}{l}\text { To ensure that a child who } \\
\text { undergoes blood draw } \\
\text { regularly will not undergo the } \\
\text { blood draw with the same } \\
\text { script as before. }\end{array}$ & $\begin{array}{l}\text { Because of a lack of programming } \\
\text { skills and time, the project group } \\
\text { was not able to program multiple } \\
\text { scripts for the same age group into } \\
\text { the design of the social robot. }\end{array}$ \\
\hline Operable by speech & $\begin{array}{l}\text { The robot must be operable } \\
\text { by speech. }\end{array}$ & $\begin{array}{l}\text { Blood draw employees are } \\
\text { busy with preparing the child } \\
\text { for the procedure and the } \\
\text { blood draw itself, thus, they } \\
\text { are not able to press any } \\
\text { buttons. }\end{array}$ & $\begin{array}{l}\text { Because of the used platform, the } \\
\text { robot could not use its camera and } \\
\text { microphone. The platform makes } \\
\text { use of the internet, and all these } \\
\text { data will also be transported over } \\
\text { the internet. This is not allowed due } \\
\text { to privacy concerns. }\end{array}$ \\
\hline Operability & $\begin{array}{l}\text { The robot must be operable by } \\
\text { using code words. }\end{array}$ & $\begin{array}{l}\text { To avoid children with a } \\
\text { mental illness getting } \\
\text { confronted with their mental } \\
\text { handicap, code words should } \\
\text { be used. }\end{array}$ & $\begin{array}{l}\text { Because of the used platform, the } \\
\text { robot could not use its camera and } \\
\text { microphone. The platform makes } \\
\text { use of the internet, and all these } \\
\text { data will also be transported over } \\
\text { the internet. This is not allowed due } \\
\text { to privacy concerns. }\end{array}$ \\
\hline Placement & $\begin{array}{l}\text { The robot must be placed on } \\
\text { the eye level of the child. }\end{array}$ & $\begin{array}{l}\text { To ensure the child has a clear } \\
\text { view of the robot. }\end{array}$ & $\begin{array}{l}\text { The attribute to get the robot on the } \\
\text { eye level of the child would be a } \\
\text { hindrance to the phlebotomist. } \\
\text { Therefore, the robot was placed on } \\
\text { the floor, about one meter distance } \\
\text { from the child. }\end{array}$ \\
\hline
\end{tabular}

\subsection{Phase B: The Impact of the Robot on Children's Pain and Anxiety}

4.2.1. FLACC and VAS Scores

In total, 158 children participated in our study. Using dataset I, outlier removal resulted in omitting 13 participants that contained outliers, which is $8.23 \%$ of the dataset. No FLACC or VAS-A score was normally distributed $(p<0.05)$ [44]. However, VAS-A scores, before (VB), during (VD) and after (VA), as well as FLACC scores before (FB), during (FD) and after (FA) were all homogeneous based on the mean $(p>0.05)($ Glass, 1966).

\subsubsection{Experimental Group versus the Control Group}

When comparing the FLACC and the VAS-A results before, during and after blood collection, tested for each moment separately, significant differences between the groups were found. Both scores before the blood draw, that is, both the VAS-A score before (VB) and the FLACC score before (FB), were significantly lower for the experimental group $(p<0.05)$ compared to the control group, as shown in Figure 1. None of the other comparisons were significantly different. Figure 1 shows the mean VAS-A and FLACC scores before, during, and after the blood collection. Details, such as the number of participants, SD and chi-square per group, can be found in the Supplementary Material online (https:/ / osf.io/nfa8k/, accessed on 23 April 2021). 
VAS-A scores

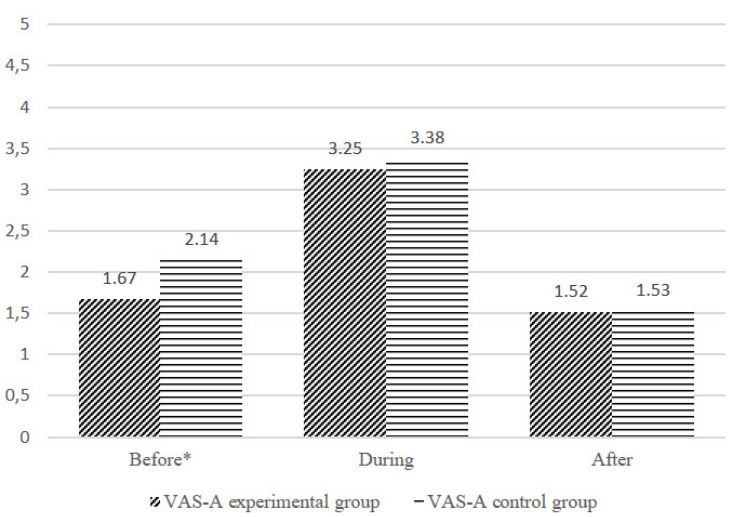

FLACC scores

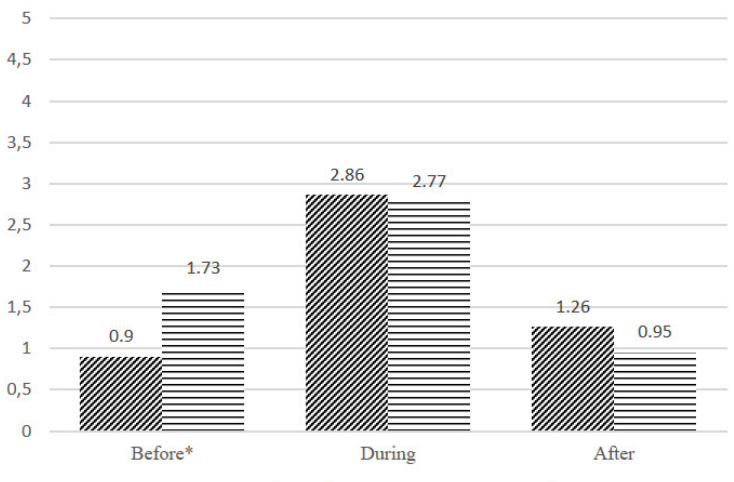

" FLACC experimental group -FLACC control group

Figure 1. Mean VAS-A and FLACC scores before, during and after the blood collection * $(p \leq 0.05)$.

When comparing the experimental group and control group per category (lower, middle and higher classes of primary education), significant differences were found between $\mathrm{VB}$ and FB in the middle classes category. Children in the middle classes category scored significantly $(p<0.01)$ lower on the VAS-A and FLACC score before the blood collection. For the lower and higher classes categories, differences were not significant. These results are shown in Figure 2. Details, such as the number of participants, SD, $p$ and chi-square per group, can be found in the Supplementary Material online (https://osf.io/nfa8k/, accessed on 23 April 2021).
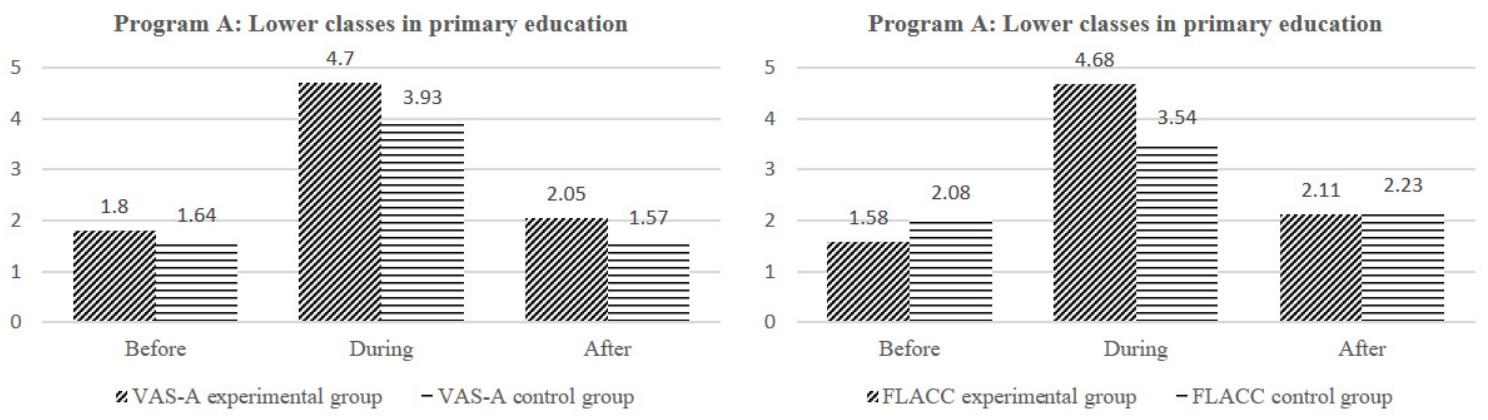

Program B: Middle classes in primary education

Program B: Middle classes in primary education
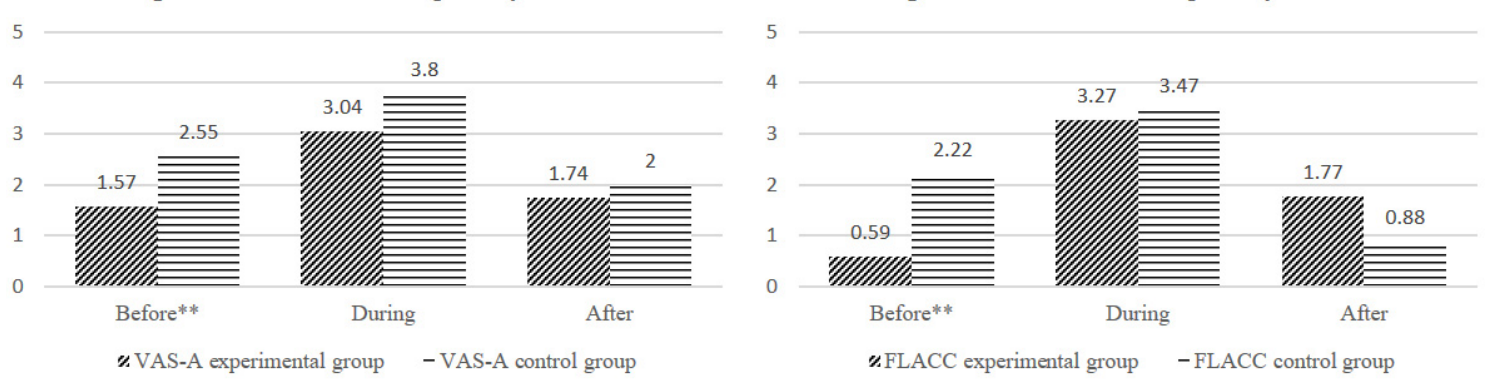

Program C: Higher classes in primary education

\% FLACC experimental group -FLACC control group

Program C: Higher classes in primary education
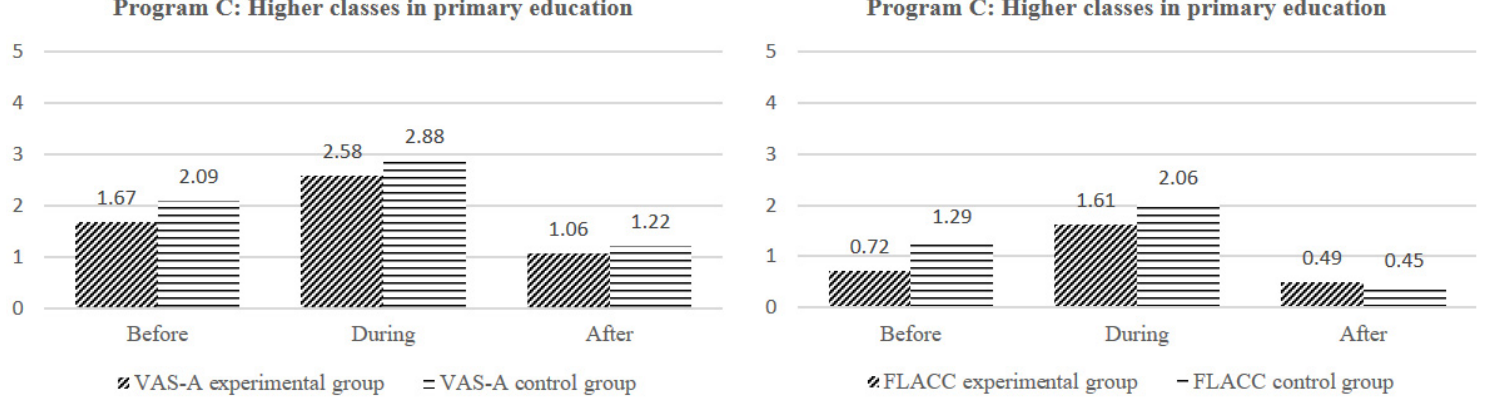

Figure 2. VAS-A and FLACC scores before, during, and after based on program/target group $\left({ }^{* *} p<0.01\right)$. 


\subsubsection{Children's Recordings of VAS-A Score}

Next to the healthcare professionals recording the VAS-A and FLACC scores, the children were also asked to rate their anxiety level after drawing blood. For dataset II, outlier removal resulted in omitting 26 participants that contained outliers (mean $\pm 2.50 \times \mathrm{SD}$ ), which is $16 \%$ of the dataset. In total, the scores of 126 children were included in this analysis, of which six cases had missing data.

Overall, the mean of the children's own reported VAS-A scores after the blood draw procedure shows a trend ( $p \leq 0.1$ ), wherein children who interacted with the robot (i.e., the experimental group) had lower anxiety scores compared to the children who did not interact with a robot, as shown in Table 4. Comparison of the experimental and control groups per category (lower, middle, and higher classes of primary education) did not show significant differences.

Table 4. VAS-A scores provided by the children.

\begin{tabular}{cccccc}
\hline- & $N$ & Missing Data & Mean & $S D$ & $p$ \\
\hline All & 126 & 6 & 1.35 & 1.71 & \\
Experimental & 69 & 3 & 1.12 & 1.65 & 0.095 \\
Control & 63 & 3 & 1.60 & 1.76 & \\
\hline
\end{tabular}

Note: VAS-A scores were rated on a smiley-based scale, which was transformed into a 0 to 10 scale for the analysis.

\subsubsection{Parents' Attitudes towards the Use of Robots during Blood Collection}

In total, the views of 132 parents were recorded regarding the stress level of the child before coming to the clinic. Additionally, the parents of children in the experimental group $(n=69)$ provided their views regarding their and their child's knowledge on robotics, their perception of the effectiveness of the robot, and if their child would like to use the robot again during blood draw. The overall survey results are shown in Table 5.

Table 5. Overall perceptions of parents and contextual information.

\begin{tabular}{|c|c|c|c|c|c|}
\hline Questions & $N$ & $M$ & $S D$ & Min & Max \\
\hline How much knowledge do you have of robotics? & 69 & 2.31 & 1.19 & 1 & 5 \\
\hline How much knowledge does your child have of robotics? & 69 & 2.12 & 1.23 & 1 & 5 \\
\hline How tense was your child before coming to the clinic? & 128 & 3.64 & 1.65 & 1 & 6 \\
\hline Do you think your child would like to be distracted by the robot? & 69 & 4.97 & 0.98 & 2 & 6 \\
\hline What was the effect of the robot on the stress and anxiety of the child? & 69 & 5.08 & 1.04 & 3 & 6 \\
\hline Do you think your child would like to use the robot again during blood draw? & 69 & 5.44 & 0.97 & 2 & 6 \\
\hline
\end{tabular}

Note: Based on a scale of 1-6 (1 being the most negative and 6 being most positive).

The results indicated that, on average, the children were relatively anxious before coming to the clinic, according to their parents (mean 3.64 on a scale of 1-6). Parents of children in the experimental group indicated that their overall knowledge of robotics and the knowledge of robotics of their children was low, that is, mean 2.31 for the parents and mean 2.12 for the children, on a scale of 1-6. The results show that all parents of the children participating in the experimental group considered the robots to have a positive effect on reducing their child's stress and anxiety (mean 5.08 on a scale of 1-6). Furthermore, on average, parents of children that interacted with the robot indicated that their child would like to use the robot again (mean 5.44 on a scale of 1-6).

No correlation was found between the parents' views on the impact of the robot and the FLACC and VAS-A scores, nor between the previous experience of the child (how many times a child needed to undergo blood collection in the past) and the FLACC and VAS-A scores. 


\section{Discussion}

The current study aimed to properly test the potential of social robots for reducing children's pain and anxiety in medical settings, using a randomized controlled trial with a relatively large sample size. Furthermore, we integrated the new technology, the social robot intervention, into the healthcare system of a blood draw with children in a policlinic at the hospital to assess its effectiveness (cf. [19]).

The first stage of the study identified the design requirements through focus group sessions with health care professionals that were implemented in a NAO robot. In the second stage of the study, this robot was tested in reducing anxiety and pain in children undergoing a blood draw through a randomized controlled experiment in a real-life hospital environment. Below, we discuss our results related to the programming design of the robot, its effectiveness to mitigate children's pain and anxiety during blood draw, and the study's strengths and limitations.

\subsection{Design of the Robot}

During our focus group sessions with healthcare professionals, requirements for a social robot for mitigating children's stress and anxiety were identified and prioritized. The most important requirements, prioritized as must haves, were relatively broad. They focused on the robot being able to interact, speak and move. The healthcare professionals also indicated that the robot should be tailored to a child's age level. This resulted in the three different scripts tailored for children in the lower, middle, and higher classes of primary education. These scripts made use of the should have design priorities, such as the robot's abilities to play games, tell jokes, sing, move its hands, and use color. Some requirements were not included in the robot design due to technical, practical and privacy reasons. Therefore, our robot made use of a scripted program, could not be operated by speech or code words, and was placed on the floor instead of on the eye level of the child.

The requirements identified by this study are, broadly speaking, in line with the design of social robots used in other studies focused on mitigating children's pain and anxiety in medical settings [20,22,24]. However, our study is, to our knowledge, the first to systematically present and prioritize design requirements for social robots for mitigating pain and anxiety for children based on the perspectives of healthcare professionals. Therefore, the requirements identified can serve as a steppingstone for other researchers who plan to use social robots as a distraction strategy for children in a medical setting. Furthermore, medical professionals who plan to use social robots with children can use this list for applying robots in their daily practice.

Due to practical reasons related to the COVID-19 pandemic, the sample size of our focus groups ranged from three to seven participants. Morgan [31], however, recommends that a focus group ideally consists of six to ten participants. Therefore, our requirements list might not be all-encompassing. Furthermore, including more empathic capabilities in a social robot could further improve the design. Social robots with empathic capabilities are demonstrated to outperform distraction robots in earlier research [49].

\subsection{Effectiveness of the Robot for Mitigating Pain and Anxiety}

The children who interacted with the robot did show statistically significant lower pain and anxiety scores compared to the control group before blood draw. Children in the middle class category (i.e., aimed at children aged approximately 6-9) who interacted with a robot showed significantly less pain and anxiety, compared to their peers in the control group. This is in line with an earlier study [20], which applied a social robot to interact with children between the age of 4-9 during their vaccination. Beran et al. [20] also found that children within this age range who interacted with a robot perceived significantly less pain and distress, compared to their peers who received standard care.

No significant results were found for the other two age categories (i.e., lower and higher classes of primary education, aimed at children aged approximately 4-6 and 9-12). For the older children (higher classes), this could be explained by the limited interaction 
capabilities of the robot. Multiple children of this category expressed the robot as limited since they quickly realized that the robot was scripted and did not respond to their questions or answers. Some children in the lowest classes' category viewed the robot as scary, or did not really understand what the robot was, or how to interact with it. This could explain why some of the mean VAS and FLASS scores of the children in the lower classes of primary education in the experimental group were higher compared to the control group. However, these differences were not significant. Furthermore, the songs for this group were, according to one parent, a bit dull for children in the lower classes age category. This could explain why no significant results were found for this age group (lower classes of primary education).

Children also expressed their anxiety levels after drawing blood. The results show an trend, wherein children who interacted with a robot were less anxious compared to children who received standard care without a robot.

The parents of the children, of all age groups, who interacted with the robot in this study showed a strong positive attitude toward the use of social robots for mitigating pain and anxiety. In their view, the robot did lower the pain and anxiety levels of their child. Furthermore, they indicated that their child would like the robot to be present during the next blood draw session.

\subsection{Strengths and Limitations}

In addition to the randomized controlled experimental design (RCT), allowing for a proper test of an intervention [50], the relatively large sample size is a clear strength of our study. In total, 158 children participated in our study, making this one of the largest experiments with social robots to mitigate pain and anxiety for children during blood collection. To compare, [20] had $N=57$; [23] included $N=86$; and [24] had a sample size of $N=139$. Furthermore, the real-life field setting of our study ensured a high level of ecological validity [51].

Some limitations related to the generalization of our results should nevertheless be noted. First, the children participating in this study were all Dutch children visiting a single hospital. Therefore, the results may not be representative outside of a Dutch (Western/European culture) context. Additionally, the hospital at which the data were collected specializes in administering blood draw to highly anxious children. Due to privacy restrictions, the researchers were not able to use the robot's camera or microphone functionalities. Therefore, the robot was unable to provide targeted answers to the children, as the microphone had to be turned off. Finally, it can prove useful to include children from the different investigated categories in the focus group to further optimize the scripts for the robot.

\section{Conclusions and Future Research}

In conclusion, our results show that purposely designed social robots can mitigate children's pain and anxiety before drawing blood in a hospital setting. In particular, children in the middle classes of primary education (approximately between the age of six to nine) showed significantly less pain and anxiety before the blood draw, compared to their younger and older peers. The parents of the children who interacted with a robot hold strong positive attitudes towards the use of social robots. These results demonstrate that social robots have great potential to serve as an additional tool to standard distraction techniques used by phlebotomists.

Our research complements the already existing literature on the potential use of social robots in healthcare settings. However, for social robots to be (more) effective and to become commonplace in the medical sector, we would like to point out several key directions for future research. First, the ease of use of the robot needs to be improved for a broader application. Currently, healthcare professionals lack the time and experience to start using the currently available robotic platforms. Second, the interaction between robot and child should be improved. Robotic speech technology is not yet sufficiently sophisticated to 
allow for autonomous spoken interaction between the robot and child in a one-on-one encounter. In addition, due to privacy restrictions, we could not create a real-life (semi) autonomous interaction between the robot and child, wherein the robot responded to individual questions or responses provided by the child or the healthcare professional. Improving the human-robot interaction could also make it more suitable for older children (i.e., beyond the age of nine); this can be a subject for further research. Then, the robot would also be able to actually interact with the child and not solely be a distraction. It is to be expected that this would increase effectiveness for all age categories. Future research might also further focus on the physical properties that might help to increase likeability or acceptance for each age group. Finally, since this study took place in one hospital, which was specialized in administering blood draw to highly anxious children, we recommend future research to also be conducted in other (general) medical settings.

Assuming that the current issues with the technological sophistication of social robots will be solved in due time, social robots might become promising tools for mitigating children's pain and anxiety during blood collection. This would then not only benefit the children involved but also, potentially, lower the workload of healthcare professionals and make the trip to a clinic more relaxed for parents.

Supplementary Materials: The following are available online at https:/ /osf.io/nfa8k.

Author Contributions: Conceptualization, M.H.J.S., K.S., L.B., T.M., N.v.P., T.T., C.S., E.A.K. and W.M.T.G.; data curation, L.B., T.M., N.v.P., T.T. and C.S.; formal analysis, L.B., N.v.P., C.S. and D.F.P.; funding acquisition, M.H.J.S.; investigation, L.B., T.M., N.v.P., T.T. and C.S.; methodology, M.H.J.S., K.S., L.B., T.M., N.v.P., T.T., C.S., D.F.P., E.M.v.d.R. and W.M.T.G.; project administration, M.H.J.S., K.S., L.B., T.M., N.v.P., T.T. and C.S.; resources, M.H.J.S. and E.M.v.d.R.; software, L.B., T.M., N.v.P. and T.T.; supervision, M.H.J.S., K.S., D.F.P. and W.M.T.G.; validation, D.F.P., E.A.K. and W.M.T.G.; visualization, M.H.J.S.; writing—original draft, M.H.J.S., K.S., L.B., T.M., N.v.P. and T.T.; writingreview and editing, M.H.J.S., K.S., D.F.P., E.A.K., E.M.v.d.R. and W.M.T.G. All authors have read and agreed to the published version of the manuscript.

Funding: This research received no external funding.

Institutional Review Board Statement: The study was conducted according to the guidelines of the Declaration of Helsinki (as revised in 2013) and was reviewed by the Medical Ethics Review Committee (METC-20-678/C) of the UMC Utrecht.

Informed Consent Statement: Informed consent was obtained from all subjects involved in the study.

Data Availability Statement: Anonymized data can be made available by the corresponding author.

Acknowledgments: We are very grateful to all children and parents who participated in our study. We also thank the health-care employees of the WKZ who participated in this study, with special thanks to the phlebotomists. Furthermore, we would like to thank the WKZ Universitair Medisch Centrum Utrecht, the Netherlands, for their guidance and for allowing us to conduct our research at their facility.

Conflicts of Interest: The authors declare no conflict of interest.

Ethical Statement: Research involving human subjects complied with all relevant national regulations and institutional policies, was in accordance with the tenets of the Helsinki Declaration (as revised in 2013) and was reviewed by the Medical Ethics Review Committee (METC-20-678/C) of the UMC Utrecht.

\section{References}

1. Kennedy, R.M.; Luhmann, J.; Zempsky, W.T. Clinical Implications of Unmanaged Needle-Insertion Pain and Distress in Children. Pediatrics 2008, 122, S130-S133. [CrossRef]

2. Uman, L.S.; Chambers, C.T.; McGrath, P.J.; Kisely, S.R. Psychological Interventions for Needle-related Procedural Pain and Distress in Children and Adolescents. Cochrane Database Syst. Rev. 2006, 4. [CrossRef]

3. Sokolowski, C.J.; Giovannitti, J.A.; Boynes, S.G. Needle Phobia: Etiology, Adverse Consequences, and Patient Management. Dent. Clin. N. Am. 2010, 54, 731-744. [CrossRef] 
4. Willemsen, H.; Chowdhury, U.; Briscall, L. Needle Phobia in Children: A Discussion of Aetiology and Treatment Options-Hessel Willemsen, Uttom Chowdhury, Louise Briscall, 2002. Clin. Child Psychol. Psychiatry 2002, 7, 609-619. [CrossRef]

5. Inal, S.; Kelleci, M. Distracting Children during Blood Draw: Looking through Distraction Cards Is Effective in Pain Relief of Children during Blood Draw. Int. J. Nurs. Pract. 2012, 18, 210-219. [CrossRef]

6. Birnie, K.A.; Noel, M.; Parker, J.A.; Chambers, C.T.; Uman, L.S.; Kisely, S.R.; McGrath, P.J. Systematic Review and Meta-Analysis of Distraction and Hypnosis for Needle-Related Pain and Distress in Children and Adolescents. J. Pediatr. Psychol. 2014, 39, 783-808. [CrossRef]

7. Arts, S.E.; Abu-Saad, H.H.; Champion, G.D.; Crawford, M.R.; Fisher, R.J.; Juniper, K.H.; Ziegler, J.B. Age-Related Response to Lidocaine-Prilocaine (EMLA) Emulsion and Effect of Music Distraction on the Pain of Intravenous Cannulation. Pediatrics 1994, 93, 797-801.

8. Cassidy, K.-L.; Reid, G.J.; McGrath, P.J.; Finley, G.A.; Smith, D.J.; Morley, C.; Szudek, E.A.; Morton, B. Watch Needle, Watch TV: Audiovisual Distraction in Preschool Immunization. Pain Med. 2002, 3, 108-118. [CrossRef]

9. Megel, M.E.; Houser, C.W.; Gleaves, L.S. Children's Responses to Immunizations: Lullabies as a Distraction. Issues Compr. Pediatric Nurs. 1998, 21, 129-145. [CrossRef] [PubMed]

10. Cohen, L.L.; Blount, R.L.; Panopoulos, G. Nurse Coaching and Cartoon Distraction: An Efective and Practical Intervention to Reduce Child, Parent, and Nurse Distress During Immunizations1. J. Pediatr. Psychol. 1997, 22, 355-370. [CrossRef] [PubMed]

11. Manne, S.L.; Redd, W.H.; Jacobsen, P.B.; Gorfinkle, K.; Schorr, O.; Rapkin, B. Behavioral Intervention to Reduce Child and Parent Distress during Venipuncture. J. Consult. Clin. Psychol. 1990, 58, 565-572. [CrossRef]

12. Cifuentes, C.A.; Pinto, M.J.; Céspedes, N.; Múnera, M. Social Robots in Therapy and Care. Curr. Robot Rep. 2020, 1, 59-74. [CrossRef]

13. Hegel, F.; Muhl, C.; Wrede, B.; Hielscher-Fastabend, M.; Sagerer, G. Understanding Social Robots. In Proceedings of the 2009 Second International Conferences on Advances in Computer-Human Interactions, Cancun, Mexico, 1-7 February 2009; pp. 169-174.

14. Belpaeme, T.; Kennedy, J.; Ramachandran, A.; Scassellati, B.; Tanaka, F. Social Robots for Education: A Review. Sci. Robot. $2018,3$. [CrossRef] [PubMed]

15. Konijn, E.A.; Hoorn, J.F. Robot Tutor and Pupils' Educational Ability: Teaching the Times Tables. Comput. Educ. 2020, 157, 103970. [CrossRef]

16. Vogt, P.; de Haas, M.; de Jong, C.; Baxter, P.; Krahmer, E. Child-Robot Interactions for Second Language Tutoring to Preschool Children. Front. Hum. Neurosci. 2017, 11. [CrossRef] [PubMed]

17. Alemi, M.; Meghdari, A.; Ghazisaedy, M. The Impact of Social Robotics on L2 Learners' Anxiety and Attitude in English Vocabulary Acquisition. Int. J. Soc. Robot. 2015, 7, 523-535. [CrossRef]

18. Logan, D.E.; Breazeal, C.; Goodwin, M.S.; Jeong, S.; O'Connell, B.; Smith-Freedman, D.; Heathers, J.; Weinstock, P. Social Robots for Hospitalized Children. Pediatrics 2019, 144. [CrossRef]

19. Dawe, J.; Sutherland, C.; Barco, A.; Broadbent, E. Can Social Robots Help Children in Healthcare Contexts? A Scoping Review. BMJ Paediatr. Open 2019, 3. [CrossRef]

20. Beran, T.N.; Ramirez-Serrano, A.; Vanderkooi, O.G.; Kuhn, S. Reducing Children's Pain and Distress towards Flu Vaccinations: A Novel and Effective Application of Humanoid Robotics. Vaccine 2013, 31, 2772-2777. [CrossRef]

21. Moerman, C.J.; Jansens, R.M. Using Social Robot PLEO to Enhance the Well-Being of Hospitalised Children. J. Child Health Care 2020, 1367493520947503. [CrossRef]

22. Farrier, C.E.; Pearson, J.D.R.; Beran, T.N. Children's Fear and Pain During Medical Procedures: A Quality Improvement Study with a Humanoid Robot. Can. J. Nurs. Res. 2019, 844562119862742. [CrossRef] [PubMed]

23. Ali, S.; Manaloor, R.; Ma, K.; Sivakumar, M.; Beran, T.; Scott, S.D.; Vandermeer, B.; Beirnes, N.; Graham, T.A.D.; Curtis, S.; et al. A Randomized Trial of Robot-Based Distraction to Reduce Children's Distress and Pain during Intravenous Insertion in the Emergency Department. Can. J. Emerg. Med. 2021, 23, 85-93. [CrossRef]

24. Rossi, S.; Larafa, M.; Ruocco, M. Emotional and Behavioural Distraction by a Social Robot for Children Anxiety Reduction During Vaccination. Int. J. Soc. Robot. 2020, 12, 765-777. [CrossRef]

25. Moerman, C.J.; van der Heide, L.; Heerink, M. Social Robots to Support Children's Well-Being under Medical Treatment: A Systematic State-of-the-Art Review. J. Child Health Care 2019, 23, 596-612. [CrossRef]

26. Harbert, K.R. Venipuncture. In Essential Clinical Procedures, 2nd ed.; Dehn, R.W., Asprey, D.P., Eds.; W.B. Saunders: Philadelphia, PA, USA, 2007; Chapter 5; pp. 47-61. ISBN 978-1-4160-3001-0.

27. Krleza, J.L.; Dorotic, A.; Grzunov, A.; Maradin, M. Capillary Blood Sampling: National Recommendations on Behalf of the Croatian Society of Medical Biochemistry and Laboratory Medicine. Biochem. Med. 2015, 25, 335-358. [CrossRef]

28. Corbin, J.; Strauss, A. Basics of Qualitative Research. In Techniques and Procedures for Developing Grounded Theory, 3rd ed.; SAGE Publications, Inc.: Thousand Oaks, CA, USA, 2008; ISBN 978-1-4129-0644-9.

29. SoftBank Robotics NAO the Humanoid and Programmable Robot I SoftBank Robotics. Available online: https://www. softbankrobotics.com/emea/en/nao (accessed on 16 September 2020).

30. Morgan, D.L. Focus Groups. Annu. Rev. Sociol. 1996, 22, 129-152. [CrossRef]

31. Morgan, D. Focus Groups as Qualitative Research; SAGE Publications, Inc.: Thousand Oaks, CA, USA, 1997; ISBN 978-0-7619-0343-7. 
32. McCormack, H.M.; Horne, D.J.d.L.; Sheather, S. Clinical Applications of Visual Analogue Scales: A Critical Review. Psychol. Med. 1988, 18, 1007-1019. [CrossRef]

33. Bringuier, S.; Dadure, C.; Raux, O.; Dubois, A.; Picot, M.-C.; Capdevila, X. The Perioperative Validity of the Visual Analog Anxiety Scale in Children: A Discriminant and Useful Instrument in Routine Clinical Practice to Optimize Postoperative Pain Management. Anesth. Analg. 2009, 109, 737-744. [CrossRef]

34. Merkel, S.I.; Voepel-Lewis, T.; Shayevitz, J.R.; Malviya, S. The FLACC: A Behavioral Scale for Scoring Postoperative Pain in Young Children. Pediatr. Nurs. 1997, 23, 293-297.

35. Nemoto, T.; Beglar, D. Developing Likert-Scale Questionnaires Campus Reference Data. In JALT2013 Conference Proceedings; Sonda, N., Krause, A., Eds.; JALT: Tokyo, Japan, 2014.

36. Bishop, G.F. Experiments with the Middle Response Alternative in Survey Questions. Public Opin. Q. 1987, 51, 220-232. [CrossRef]

37. Presser, S.; Schuman, H. The Measurement of a Middle Position in Attitude Surveys. Public Opin. Q. 1980, 44, 70-85. [CrossRef]

38. Olesen, V.; Droes, N.; Hatton, D.; Chico, N.; Schatzman, L. Analyzing Together: Recollections of a Team Approach, 1st ed.; Routledge: London, UK, 1994; pp. 125-142. ISBN 978-0-203-41308-1.

39. van Eemeren, F.H.; Garssen, B.; Krabbe, E.C.W.; Snoeck Henkemans, A.F.; Verheij, B.; Wagemans, J.H.M. Toulmin's Model of Argumentation. In Handbook of Argumentation Theory; Springer: Dordrecht, The Netherlands, 2014; pp. 203-256. ISBN 978-90-481-9473-5.

40. Stewart, D.; Shamdasani, P.N.; Rook, D.W. Analyzing Focus Group Data. In Focus Groups; SAGE Publications, Ltd.: Thousand Oaks, CA, USA, 2007; ISBN 978-0-7619-2583-5.

41. Namey, E.; Guest, G.; Thairu, L.; Johnson, L. Data reduction techniques for large qualitative data sets approaches to data analysis. In Handbook for Team-Based Qualitative Research; AltaMira Press: Lanham, MD, USA, 2008; Volume 2, pp. 137-161.

42. Maciaszek, L.A.; Loucopoulos, P. (Eds.) Communications in Computer and Information Science. In Evaluation of Novel Approaches to Software Engineering: 5th International Conference, ENASE 2010, Athens, Greece, 22-24 July 2010, Revised Selected Papers; Springer: Berlin/Heidelberg, Germany, 2011; ISBN 978-3-642-23390-6.

43. Aguinis, H.; Gottfredson, R.K.; Joo, H. Best-Practice Recommendations for Defining, Identifying, and Handling Outliers. Organ. Res. Methods 2013, 16, 270-301. [CrossRef]

44. Yazici, B.; Yolacan, S. A Comparison of Various Tests of Normality. J. Stat. Comput. Simul. 2007, 77, 175-183. [CrossRef]

45. Hecke, T.V. Power Study of Anova versus Kruskal-Wallis Test. J. Stat. Manag. Syst. 2012, 15, 241-247. [CrossRef]

46. Nachar, N. The Mann-Whitney U: A Test for Assessing Whether Two Independent Samples Come from the Same Distribution. TQMP 2008, 4, 13-20. [CrossRef]

47. Myers, L.; Sirois, M.J. Spearman Correlation Coefficients, Differences between. In Encyclopedia of Statistical Sciences; American Cancer Society: Atlanta, GA, USA, 2006; ISBN 978-0-471-66719-3.

48. Gautheir, T.D. Detecting Trends Using Spearman's Rank Correlation Coefficient. Environ. Forensics 2001, 2, 359-362. [CrossRef]

49. Trost, M.J.; Chrysilla, G.; Gold, J.I.; Matarić, M. Socially-Assistive Robots Using Empathy to Reduce Pain and Distress during Peripheral IV Placement in Children. Pain Res. Manag. 2020, 2020, e7935215. [CrossRef] [PubMed]

50. Chalmers, T.C.; Smith, H.; Blackburn, B.; Silverman, B.; Schroeder, B.; Reitman, D.; Ambroz, A. A Method for Assessing the Quality of a Randomized Control Trial. Control. Clin. Trials 1981, 2, 31-49. [CrossRef]

51. Frey, B.B. Ecological Validity. The SAGE Encyclopedia of Educational Research, Measurement, and Evaluation; SAGE Publications, Ltd.: Thousand Oaks, CA, USA, 2018. 